\title{
«RAZA" Y RELIGION EN LA ESPAÑA DE LOS SIGLOS XV Y XVI: UNA REVISION DE LOS ESTATUTOS DE «LIMPIEZA DE SANGRE»
}

\author{
John Edwards \\ Universidad de Birmingham
}

En los primeros años del siglo XIX, cualquier estudiante que deseaba obtener una beca del Colegio Mayor de Fonseca de la Universidad de Santiago recibía un impreso que contenía siete preguntas. Cinco testigos tenían que decir, para el candidato, al juez o magistrado del pueblo del testigo, si el estudiante era o no la persona que pretendía ser, si un hermano suyo habia recibido anteriormente una beca del mismo colegio, y si el candidato era hijo legítimo de sus padres. Sin embargo, el objeto principal del interrogatorio se encontraba en la pregunta número 4 :

«Si sabe (el testigo) que, así dicho Colegial electo, como sus Padres, Abuelos y Bisabueloș por las respectivas líneas han sido y son tenidos, y reputados por Cristianos Viejos, sin raza ni mezcla de judío, Moro o Converso; y que no han sido condenados por el Santo Oficio de la Inquisición como Hereges o sospechosos de la Fe» (1).

En 1935, el Reichsgesetzblatt del 14 de noviembre publicó el artículo 2 de las leyes de Nüremberg:

"Un individuo con la sangre judía mixta ("ein Jüdische Mischling») es uno que desciende de uno o dos abuelos que fueron judíos completos de raza. Un abuelo se considera como judio completo de raza si pertenecia a la comunidad religiosa judía («eine jüdischen Religionsgemeinschaft»). 
Además, en el artículo 5:

«Se considera como judío cualquier persona que desciende de tres abuelos, a lo menos, que fueron judíos completos de raza» (2).

Esta discusión tratará de comentar los estatutos españoles de «limpieza de sangre» y también de indicar algunos, así como varios antecesores de las producciones legalísticas del Tercer Reich. Comenzará con una idea general de la introducción y desarrollo de los estatutos españoles de «limpieza de sangre» entre c. 1499 y c. 1500 , seguido de un estudio de la teoría y de la actividad intelectual que sostenian estos estatutos. Después se examina la práctica, en detalle, de la «limpieza de sangre» en España, y la conclusión será una comparación entre las opiniones de los españoles de los siglos XV y XVI sobre los judíos y las del siglo $X X$.

En mayo de 1449, el alcaide de Toledo, Pero Sarmiento, publicó el documento que se conoce para la historia como la Sentencia-Estatuto, diciendo que «todos los dichos conversos descendientes del perverso linaje de los judíos, en cualquier guisa que sea....sean habidos e tenidos como el derecho los ha e tiene por infames, inhábiles, incapaces e indignos para haber todo oficio e beneficio público y privado en la dicha cibdad de Toledo, y en su tierra, término y jurisdicción». Aunque Sarmiento tenía su oficio de la Corona, el alcaide, junto con su ciudad, era ya un rebelde contra Juan II de Castilla desde principios del año 1449. El condestable de Castilla, don Alvaro de Luna, habia solicitado de Toledo un servicio, y algunos ciudadanos habían atacado a un arrendador converso, Alonso Cota, y a algunos otros conversos. La revuelta no llegó a extenderse por la tierra de Toledo, a pesar de las provisiones de la Sentencia-Estatuto. Al contrario, en marzo de 1451, Juan II perdonó a todos los vecinos de Toledo. Sin embargo, el concepto de la "pureza» o «limpieza de sangre», que se divulgó por primera vez de forma pública en esta misma ciudad durante la rebelión de 1449, se convertiría en tema de la historia española durante los siglos siguientes, e incluso a finales del siglo XX alimenta, en la mente de algunos extranjeros, la «Leyenda Negra» (4). En principio, el debate sobre el concepto toledano, es decir, lo de excluir de los oficios públicos a algunos individuos a causa de su origen racial, se restringió a la actividad literaria y propagandística. Sin embargo, se vieron implicados en el asunto algunos personajes con influencias en el campo de la política o de la religión, los de la Corte castellana y los de la Curia romana. Entre los protagonistas, algunos eran de origen judío y otros no, pero todos discutían lo que se veía, cada vez más, como un problema político y social dentro de 
la Corona de Castilla, es decir, el avance rápido en la Iglesia y en toda la sociedad de los más hábiles e inteligentes de los que se habían convertido del Judaismo al Cristianismo, bajo las presiones de la violencia, de la actividad misionera y de la legislación restrictiva contra los judios entre los años 1391 y c. 1420 (5). Los intelectuales continuaban con sus debates y proponían varias soluciones, por ejemplo, una Inquisición para comprobar la ortodoxia de los conversos, pero, al mismo tiempo, varias corporaciones públicas en Castilla empezaban a imitar el ejemplo de los rebeldes toledanos.

Como el producto de un regimiento ilegal, la Sentencia-Estatuto de 1449 fue anulada desde el primer momento en que se produjo la restauración del gobierno real en Castilla y durante los próximos quince años no se promulgaron más disposiciones de este tipo. Sin embargo, antes de indicar las líneas generales de las leyes de limpieza de sangre hasta cerca del año 1600 hay que destacar su contexto legislativo. En primer lugar, no hubo nunca una ley «nacional» y general para toda la Corona de Castilla o, evidentemente, en los demás reinos hispánicos, bajo el régimen de los Habsburgo, después de 1516; así que las Cortes castellanas nunca promulgaron un estatuto de limpieza y la administración real nunca dió una provisión o decreto de este tipo. Al contrario, los estatutos de limpieza de sangre aparecieron sin un sistema fijo y cada uno se aploicó a un solo cuerpo social específico, en un lugar concreto, tal como un cabildo catedralicio, una capilla privada, una orden militar o religiosa, un colegio mayor universitario o un gremio, sin que importara si este último era una cofradía religiosa o ( $y$ frecuentemente no hubo mucha diferencia) un sindicato industrial o comercial. Con el paso del tiempo, al cabo de muchos decenios, la Inquisición misma aceptó las reglas de limpieza de sangre para sus familiares. España, igual que cualquier otra sociedad bajomedieval o moderna, se entendía como un conjunto de corporaciones, diversas y distintas, bajo el mando de Dios y del rey, y cada una celosa defensora de sus libertades y privilegios. Este hecho tuvo una influencia esencial en el desarrollo de los estatutos de limpieza en España y también en Ultramar. El contraste entre las condiciones del gobierno en España en los siglos XV y XVI, y la naturaleza monolítica del régimen y la sociedad en la Alemania nazi es obvio, aunque cada sistema encontró muchos y grandes problemas en el cumplimiento de las leyes sobre el origen genético de los individuos humanos.

No fue en Toledo sino en Córdoba, una ciudad que tenía una tradición de convivencia de cristianos, judíos y musulmanes, donde se siguió el ejemplo de la Sentencia-Estatuto, según los documentos que han visto la luz hasta nuestros días. En 1446 el chantre de la catedral, don Fernando Ruiz de Aguayo, hizo un estatuto para los seis capellanes y dos sacristanes que iban a ser- 
vir en el altar de su nueva capilla familiar, dedicada al martir, mítico al parecer, San Acasio, cuyo culto había sido muy difundido en la época de las cruzadas del siglo XII. El chantre ordenó que ningún individuo de origen de sangre judía podría ocupar uno de estos puestos, «non enbargante que en esta generación de conversos ay munchas virtuosas e buenas personas e de buena consçiençia e vida». Explicó que, no obstante, quería excluir a dicha gente, porque afirmó que dos primos suyos, que eran miembros de la baja nobleza cordobesa, activos en la política en el territorio, habian sufrido, de una manera u otra, en manos de unos conversos anónimos(6). En 1471, lo más tarde, una nueva cofradía, llamada de la Hermandad de la Caridad, se fundó en la ciudad, y sus estatutos excluyeron especificamente a los que fueran de origen judío. Es muy probable que no fuera por casualidad que una procesión de esta misma cofradía en honor de la Virgen María, durante la Cuaresma de 1473, terminase en una oleada de violencia contra los conversos de Córdoba. Nobles, obreros y artesanos atacaron a los conversos después de la caida, o de arrojar agua, o, como dijeron algunos, de orina, desde la casa de un converso sobre una estatua de la Virgen María. Como consecuencia muchos miembros ricos de la comunidad mercantil de Córdoba, que eran de origen judío, murieron o recibieron heridas, vieron saqueados y robados sus bienes, o se tuvieron que escapar a otras ciudades o villas, donde recibieron más protección. Además, el concejo municipal, que en esta época estaba bajo el mando del jefe del bando más poderoso de Córdoba, don Alonso de Aguilar, quien, como alcalde mayor, no había sido capaz de terminar con el alboroto, pregonó una ordenanza por la que todos los conversos quedaban excluidos de cualquier oficio público en la ciudad o en su tierra (7). Esta ley también fue suprimida rápidamente cuando los Reyes Católicos restauraron la autoridad real, perdida ya, antes de 1473-74, por su antecesor Enrique IV. Sin embargo, los estatutos de limpieza de sangre continuaron su marcha, lenta e irregular, por las instituciones del país.

En 1486 el estatuto de limpieza tocó, por primera vez, una orden religiosa dentro de la Iglesia Católica. La nueva Inquisición en Castilla pretendió que había encontrado muchos creyentes y practicantes de la religión judía entre los frailes jerónimos, que ponían el acento en la vida solitaria y eremítica mucho más que en la vida comunal. En lo sucesivo, ninguna persona de sangre judía recibiría la licencia para entrar en la órden. Los intentos por aplicar medidas similares en la órden de Predicadores fracasaron durante los años noventa del siglo $\mathrm{XV}$, con excepción de un sólo priorato, y aún allí se diluyeron muy pronto las provisiones reformadoras. No obstante, un lento progreso, todavía sin sistema fijo, continuaría entre las órdenes religiosas y los cabildos catedralicios durante el siglo XVI. De esta forma, la muy conocida casa bene- 
dictina reformada de Montserrat adquirió un estatuto de limpieza en 1502, así como la provincia española de la Observancia Franciscana en 1525, en cabildo catedralicio de Sevilla en 1515 y el de Córdoba en 1530. Aquí, como más tarde pasó en Toledo, el experimento de una sola capilla se difundió, en este caso al cabo de más de sesenta años a toda la institución. Por aquel entonces, los estatutos de limpieza de sangre empezaron a aparecer entre los gremios, tal como el de los candeleros en Barcelona en 1498, aunque hubo una región que excluyó, después de 1482, a cualquier inmigrante converso: el señorío de Vizcaya (8). Es una ironía que no fue antes de 1547 en que la idea del estatuto de limpieza regresó a su ciudad de origen, cuando el cabildo de la catedral imitó a la capilla privada de los Reyes Nuevos, haciendo un estatuto de este tipo. Sin embargo, su arzobispo, Juan Fernández Silíceo, llegó a este punto con mucha dificultad, no solamente a causa de los intereses de los clérigos conversos, sino también al nivel de la controversia intelectual. Las cuestiones en debate durante los años de 1449 a 1451 permanecían todavía vivas un siglo más tarde y continuaron así hasta los primeros años del siglo XVII. Hacia el año de 1600 algunos pensadores empezaban a culpar a los estatutos de limpieza de la decadencia de la influencia política y económica de la España de la época (9). No obstante, es necesario examinar más atentamente dichas teorías y las ideas que sostenían estos estatutos.

Había dos influencias sobre el pensamiento español de esta época en lo que tocaba a la relación entre la «sangre», es decir, el origen genético de una persona, y la conducta humana. Evidentemente, una de estas influencias fue la Biblia, junto con las obras de los Padres de la Iglesia y de los escolásticos medievales. Las Sagradas Escrituras hebreas, y también griegas, muestran una profunda preocupación, en varias ocasiones, sobre la genealogía humana y también con la idea de que un descendiente sería castigado a causa de los pecados de su antecesor, aunque no hubiera nacido en la época del delito original (10). Es posible sostener, entonces, que las Escrituras de la Iglesia, sin contar con loos comentarios que se han hecho después de ellas, oscurecieron ya la distinción entre las categorias biológicas y morales, y las que son religiosas, tal como se ve en el Nuevo Testamento, en lo referente a las supuestas dimensiones morales de la enfermedad (11). Los aspectos religiosos del pensamiento que se encuentra detrás de los estatutos de limpieza de sangre se considerarán en su propio lugar, pero tales medidas expresaban también las teorías de la ciencia medieval sobre la reproducción humana. Como escribió acertadamente el padre Noonan: «Todos estarán de acuerdo en que un conocimiento de la biología no se incluyó en la revelación cristiana»; como consecuencia, esta falta tenía que ser compensa- 
da por otra parte, y, como era habitual en la época, la fuente más importante fue la ciencia y la medicina griega (12).

Todas las teorías clásicas acordaban al varón el papel principal en la creación. Aristóteles afirmó que la mujer suministra la materia del embrión, mientras que el hombre le da su forma y movimiento. Proporcionó una imagen para ilustrar esta constatación:

"Compárese la coagulación de la leche. Aquí la leche es el cuerpo, y el zumo de higo, o el cuajo, contiene el principio que lo hace cuajar" (Sobre la generación de los animales, lib. 1).

La sangre menstrual era la materia prima, mientras que el esperma no contenía ninguna sustancia material; más bien, se evaporaba después de la formación de la sangre y del comienzo del movimiento vital. Mucha de la filosofía griega despreciaba la materia o lo material y hacía una distinción entre la "forma», que era noble y masculina, y la «materia», que era envilecida y femenina. Aunque los autores del Bajo Imperio mostraban la tendencia a oscurecer esta distinción, las consecuencias para los estereotipos sexuales son evidentes y continuaron, de una forma comprehensiva, hasta el mundo medieval y moderno. Como consecuencia, el papel femenino en la reproducción humana parecía bestial e inferior, mientras que el varón cumplia la «función espiritual, noble e infinitamente superior, la de dar la vida» (Warner, pág. 40). El gran teólogo sistemático del siglo XIII, Santo Tomás de Aquino, creyó éso, y aún en la Inglaterra del siglo XVII, el gran investigador de la circulación de la sangre, William Harvey, creyó lo mismo (13). Sin embargo, a pesar de los estereotipos sexuales que se encontraban dentro de estas teorías, había un sentido en el que se veía a la madre con un papel más que puramente físico en la formación del nuevo ser humano. Esta creencia no aumentó, sin embargo, la ganancia de las madres judías o conversas. Aunque sería un error suponer que los modos modernos y científicos del pensamiento no eran conocidos por la gente medieval, hay que reconocer que muchos de los pensamientos y consideraciones que entraron en la mente de los que tomaban en serio la ciencia genética y la ginecología no tendrían una parte, justa o injusta, en las discusiones de hoy día. Juegos de palabras, tales como la vulva (término general para todos los órganos sexuales femeninos) "volvendo", se consideraban como aportaciones serias al debate sobre la biología, mientras que se daba mucha importancia a los contrastes, tales como el de «caliente-frígido», así como a la ciencia de la astrología.

Además, una de las creencias más profundas de los médicos y científicos medievales, y también de los teólogos y legisladores, era la de que los 
órganos sexuales de la mujer eran exactamente equivalentes a los del hombre, pero que se encontraban dentro del cuerpo, y no al exterior. De esta forma se creía no sólo que las mujeres, así como lo suponía el griego Galén, daban a luz a uno o dos críos, según el número de receptáculos de su matriz llenados por el esperma - y esta cantidad dependía de la potencia sexual del padre-, sino que también las mujeres tenian sus propios testículos dentro de su cuerpo, que producian un esperma femenino, que tendría que combinarse con el esperma del hombre para engendrar un niño. Se creía que el esperma masculino tenía su origen en los sesos y viajaba por las venas para llegar a los testículos, pero que ya tenía su color blanco, en vez del rojo normal de la sangre. Estas venas suministrarían a los sesos, en su entorno, su alimento, bajo la forma de una sangre blanqueada; de esta manera, el esperma era la «quintaesencia» del fluido nutritivo, es decir, la sangre. El «esperma» femenino, por el contrario, se veía como más basto y más húmedo que el del hombre; el «humor» de la humedad se veía como poco atractivo, desde el punto de vista sexual (14).

Sin embargo, hay otro aspecto del pensamiento científico medieval que sería muy significativo para el fondo intelectual de las leyes españolas de limpieza de sangre. Se trata del enlace que era percibido entre la sangre de una persona y la leche de su madre. Tres ejemplos permiten ilustrar la fuerza que tenía dicha creencia en la sociedad de la Europa occidental. El primero se refiere a la ciudad aragonesa de Teruel, hacia 1480. Un mozo llamado Jaime Palomos, cristiano viejo, testificó delante del inquisidor durante el proceso contra su patrona, la conversa Brianda Beswant, esposa del mercader Luis de Santangel. Contó una historia de lo que pasó un día en la cocina de su ama. Una nodriza judía estaba dando de mamar a la hija de Brianda, llamada Aldolica. Viéndolo, el mozo dijo a Brianda:

—Para qué das a tu hija de la leche de aquella perra judía?.

Ella contestó: «Non es perra».

Jaime dijo, siguiendo sin duda lo que había aprendido o en casa o en la iglesia:

«Sí es, que los judíos mataron a Nuestro Señor».

La respuesta de Brianda: —«i lo mataron, él se lo quiso», refleja, evidentemente, muchas preguntas sobre la interpretación cristiana del plano divino, que son, al menos, sugestivas. Pero lo que importa aquí es lo que implican las palabras de Jaime, es decir, que la acción de beber la leche de la nodriza transmitiría a la niña, de manera cierta, las características judías, que eran malas $y$ anticristianas (15). 
El segundo caso procede de Florencia. Alli, a pesar de sus dudas, muchos de los padres más acaudalados tenían la costumbre de entregar sus niños a nodrizas, que en muchos casos vivían en el contado de la ciudad, pero que continuaban preocupándose de las posibles consecuencias. La opinión médica de la época tenía su influencia sobre ellos. Los médicos decían que, visto que la leche de la madre se derivaba de la sangre menstrual, una nodriza, igual que la madre que amamantaba a su propio crío, contribuiría a formar al niño a su propia imagen, a pesar del papel dominante del varón, en el acto de su concepción. Estos conceptos se encontraban, evidentemente, entre las creencias del artista, y también investigador del cuerpo humano, Leonardo da Vinci. En un dibujo de 1492 ilustró las venas que subían de la parte superior del útero de la mujer para transportar a sus pechos la sangre menstrual (16). Es muy problable que puedan rastrearse ciertos restos de estas ideas en un caso acontecido en 1943, en el cual el Ministerio alemán de Justicia hizo saber a Adolfo Hitler el hecho de que una mujer judía había vendido su leche a un pediatra, sin revelar sus orígenes raciales. Los clientes cuyos niños habían recibido esta leche habían sido «agraviados», según el Ministerio, porque la leche de una judía «no se podía considerar como alimento para niños alemanes» («weil die Muttermilch einer Jüdin nicht als Nahrung für deutsche Kinder gelten kann»). Sin embargo, no se hizo nada por parte del gobierno con el fin de no sembrar la alarma entre los padres de estos niños (17).

Tales creencias, que estaban de acuerdo con el conocimiento científico del momento, quedaban detrás, no solamente en la Sentencia-Estatuto de Toledo, sino también en las opiniones de los cronistas y teóricos españoles de los dos siguientes. De esta forma, el sacerdote y cronista Andrés Bernaldez escribió en su historia de los reinados de Fernando e Isabel, que, al contrario de la opinión de los papas y de los teólogos, el judaísmo se transmitía por la sangre y, entonces, el sacramento del bautismo no lo podía quitar (18). Casi en la misma fecha, el Diccionario de los Inquisidores, publicado en Valencia en 1494, dijo, bajo el título de "Apostasía», que «los judíos transmiten de uno a otro, del padre al hijo, por la sangre, la perfidia de la antigua Ley» (19). Evidentemente, en el siglo XVI, Juan de Pineda aconsejó que las autoridades políticas evitasen una situación en la cual:

«mujer morisca ni de sangre de judíos criase a hijo de cristianos viejos, porque aún les sabe la sangre a la pega de las creencias de sus antepasados, y sin culpa suya podrían los niños cobrar algún resabio que para después les supiese mal; y muchas veces oí decir a un hombre de buen seso y conversación, que medio cuarto, que tenía de judío, nunca dejaba de importunar que se tornase judío» (20). 
Como observó Julio Caro Baroja, hay una conexión evidente entre un "criterio moral y un criterio biológico, o si se quiere, entre la religión y la patología" (21).

Esta patologia ha sido sujeta, recientemente, al examen de R.I. Moore, en un estudio que tiene por conclusión que las mentalidades que aparecieron en los siglos $X V$ y $X V$ l eran productos de los cambios de los siglos $X I$ y XII. Durante los años transcurridos entre 1050 y 1200.

«La persecución se convirtió en normal. Eso es decir no sencillamente que los individuos estaban sujetos a la violencia, sino también que una violencia, intencionada y aprobada por la sociedad, empezó a dirigirse por medio de las instituciones establecidas, o gubernamentales, o jurídicas, o sociales, contra ciertos grupos de personas que eran definidos por sus características, tales como su raza, su religión o su manera de vida, y que el mismo hecho de ser miembro de un tal grupo llegó a ser suficiente, en sí mismo, para justificar estos ataques"

Moore considera como grupos de esta categoría a los judios, los herejes cristianos, pero también a los homoxexuales masculinos y a los leprosos. A estos grupos es posible añadir, para los siglos $X V$ y XVI, a las prostitutas, los gitanos, los «indios» americanos, y aun los animales y las plantas, que se veían en este periodo, con crudeza, como sujetos al hombre y bajo su merced $y$, evidentemente, no a la mujer (22). El caso de los leprosos tiene una importancia especial para la teoría y la práctica de las leyes de limpieza de sangre. Parece que hubo una obsesión masculina durante la Edad Media en lo referente a las mujeres y su relación con «el esperma de un leproso» («sperma leprosi»). Según esta teoría, si un hombre tenía relaciones sexuales con una mujer que ya había hecho lo mismo con un leproso, el segundo amante contraería también la lepra. De esta manera, la lepra llegó a tener una estrecha relación con el acto sexual y con el pecado de la «uxuria», así como puede verse en el caso de la confesión del estudiante Arnaud de Verniolles delante del obispo de Pamiers, Jacques Fournier, a principios del siglo XIV. Sobre todo, se creía que la mujer podía, sin saberlo y sin sufrir de ello, «traer» y transmitir la lepra. El paralelismo existente con el SIDA en nuestros días es evidente. En este contexto, la naturaleza «interna» de los órganos sexuales de la mujer contribuyó a acrecentar la sospecha masculina del sexo femenino, visto que sólo existía una posibilidad del cinco por ciento de que un hombre descubriera la infección en su amante femenina (23).

El concepto de la lepra como castigo del pecado aparece en el Islam, en el Hinduismo y también en el Cristianismo, aunque en el Judaismo (Levíti- 
co 13:54-6) las acciones malas se ven nada más que como una entre muchas causas de la impureza ritual, y no como el resultado de la capacidad natural para el pecado. Sin embargo, antes del año 1100, las enfermedades de la piel, muchas veces distintas de la lepra, según la ciencia contemporánea, se relacionaban, como lugar común, no solamente con el pecado sexual, sino también con la herejía religiosa. En su petición de 1177 para la ayuda de la Cristiandad en la represión contra la herejía cátara dentro de sus tierras, el conde Ramón de Tolosa habló del catarismo como la «tabies» de la herejía, es decir, como una especia de llaga podrida que surge de una enfermedad venérea. De esta forma, «se creía que la lepra se transmitía sexualmente y por herencia, con el resultado de aumentar la líbido y de hinchar los órganos genitales». Además, ya en el siglo XII, los judíos se encontraban relacionados, en la mentalidad cristiana, con los leprosos y los herejes, que trabajaban sin cesar para la destrucción de la Cristiandad.

«Se creía también que los judíos se parecian a los herejes y a los leprosos, porque tenían una asociación con la suciedad, con el hedor y con la putrefacción, en un apetito y una dotación sexuales que eran excepcionales, y en la amenaza que ofrecían, como consecuencia, a las mujeres y a los hijos de cristianos honestos".

Como constata Moore, «las imágenes y las pesadillas no son siempre coherentes, pero siempre alimentan el mismo miedo» (24).

Detrás de estos miedos, que se proyectaban sobre tantos grupos marginados y sin privilegios en la Baja Edad Media y en la Edad Moderna, se encontraban, entre los cristianos, la sospecha y el miedo profundo hacia las mujeres, que se relacionaban estrechamente con la doctrina cristiana del «Pecado Original». Lo paradójico de esta doctrina para las relaciones entre los sexos empieza, en cierta forma, con el texto de la epístola de San Pablo a los Galateos (3:28), que se utilizaba por la Curia romana y por los conversos españoles para defender el derecho de los judíos bautizados a integrarse en la sociedad española del siglo XV:

«En Cristo no hay judío ni griego, no hay siervo ni hombre libre, no hay hombre ni mujer, porque sois todos uno en Cristo Jesús".

Sin embargo, esta misma religión ha dado siempre la impresión de odiar y temer al sexo. En particular los Padres de la Iglesia, tales como San Agustín y su maestro San Ambrosio de Milán, quienes hicieron su propia adaptación de las narraciones del Génesis sobre el Jardín del Edén con el fin de responsabilizar a Eva de la caida definitiva de todos los seres humanos, ya que ella 
fue la que comió la fruta del conocimiento del bien y del mal cuando se la ofreció la serpiente, y también convenció a Adan para que la comiera. Agustín vio el casamiento simplemente como un instrumento para limitar la «luxuria», mientras que Ambrosio dijo que «la virginidad es la única cosa que nos proteje de ser bestias». De esta forma, según Agustín, aunque un cristiano era, como dijo Pablo, salvado por el bautismo, continuaba teniendo la «peste» de la concupiscencia (en la terminología agustiniana), lo que significa que el "vicio» de conseguir placer de las cosas creadas, y sobre todo de las relaciones sexuales, en lugar del Creador mismo. La consecuencia fue que:

\begin{abstract}
«todo niño que nace en el mundo recibe la transmisión del pecado por la copulación de sus padres, y así se encuentra condenado a la perdición eterna. El sexo es el método por el cual el Pecado Original se transmite (así como una enfermedad venérea que infecta la naturaleza más profunda del hombre) porque desde entonces es imposible que las personas tengan relaciones sexuales entre ellas sin concupiscencia» (25).
\end{abstract}

Asi es que el desarrollo de la doctrina cristiana, en lo que se refiere al resultado de la conducta de Adán y Eva en el Jardín del Edén, más que la historia original narrada en el libro del Génesis, tuvo la máxima influencia en el pensamiento que se encontraba detrás de los estatutos españoles de limpieza de sangre.

La degradación de las mujeres, como resultado de la enseñanza cristiana, también torcía las ideas judías sobre la pureza y la santidad, ya que las condiciones de la pureza ritual, en los términos de acceso al Templo de Jerusalén, se convirtieron, en la tradición cristiana, en la exclusión permanente, y aún genética, de las personas no favorecidas de los nuevos «Templos", es decir, los sitios del culto cristiano. De la misma forma, en el lenguaje político, la «limpieza» llegó a ser un término significativo, que podía expresar unos sentimientos antiguos y respetados de los cánones sociales y constitucionales. En Córdoba, por ejemplo, el resentimiento por las exigencias, siempre crecientes, de la Corona en mano de obra, en el material militar, y en los impuestos, durante el periodo entre la muerte de Isabel en 1504 y la derrota de la revuelta de las Comunidades en 1521, se expresó en la declaración repetida de que, no solamente la ciudad había cumplido con su deber en el éxito de la guerra granadina, sino que Córdoba era, también, «limpia» de las manchas de su honor (esta última es también una palabra significativa al nivel de las emociones en la España de la época), que algunas personas habían insinuado (en particular el inquisidor fracasado Diego Rodríguez Lucero), en las acusaciones hechas de que la ciudad hubiese contenido algunas, o muchas, «sinagogas» ilegales durante los años anteriores a 1508. De esta forma, en 1521, 
el concejo cordobés rechazó, con indignación, una propuesta general del cardenal Adriano, según la cual se debía componer una genealogía de todos los conversos de la ciudad, con el fin de ayudar al trabajo de la Inquisición (26). Así es que, aunque las autoridades de Córdoba pudiesen menospreciar y degradar a las mujeres judías, sin embargo, veían su propia ciudad como si ella misma fuera una mujer "violada» y maltratada, en los términos de las actitudes gubernamentales de la época.

Los datos que han sido presentados hasta aquí podrian dar la impresión de que en la Castilla de los Reyes Católicos y de sus sucesores existía una intención, cada vez más fuerte, de eliminar a las personas de origen judío de la vida pública. De esta forma, sería posible atribuir los retrasos en la puesta en marcha de tal procedimiento, no a una falta de voluntad, sino más bien a una incompetencia. Sin embargo, una investigación detallada de las leyes específicas de limpieza de sangre demuestra que no solo hubo muchos y grandes obstáculos contra la eficacia ideológica, sino también que otras muchas consideraciones entraron en el proceso. Los primeros estatutos, tales como el de Toledo de 1449 y los de Córdoba de 1466 y 1473, excluyeron a todos los que tenían una gota de sangre judía, aunque pronto quedó claro que una aplicación minuciosa de tales leyes sería totalmente imposible, dada la coexistencia durante tantos siglos de los judíos y los cristianos en el país. El estatuto del cabildo de la catedral de Córdoba, que se adoptó en 1530, fue el primero del tipo que indicó los métodos para seguir en la investigación de los origenes de los candidatos a los oficios de la Iglesia Mayor.

La preocupación de esta misma ciudad por la «limpieza» de su sangre y por su «honor» a la Corona ya han llamado la atención. De esta forma, no sorprende que la Mezquita-Catedral se vió en 1530 como «la más limpia yglesia desta mácula (es decir, de la sangre judía o herética) que otra yglesia destos reynos". No obstante, el nuevo estatuto, que suscitó la controversia y que no fue aprobado por Roma antes de 1555, y ello solamente tras la intervención de Juan de Toledo, obispo de Córdoba en la fecha de su promulgación, descendió de las alturas del lenguaje que habla de la sangre y del honor, para preocuparse de los detalles del procedimiento. El candidato a cualquier oficio catedralicio tendría que jurar, de rodillas, con la mano derecha puesta sobre el crucifijo entre las páginas de un misal, que no era descendiente de judío o de moro. Tendría que indicar los nombres y lugar de nacimiento de sus padres y de sus abuelos, y, después, estos detalles serían averiguados por' el ordinario en el proceso, así como por dos personas nombradas por el cabildo catedralicio. Si fuera necesario se realizarian investigaciones similares fuera de la ciudead de Córdoba, pagándose una ayuda de costes al 
individuo que realizara dicha misión. Hay que hacer notar que era el candidato el que elegía a sus testigos, por lo que se supone que éstos no serían sus enemigos capitales. Además, es interesante destacar que, después de la entrega del resultado de la pesquisa, el cabildo votaría por mayoría sencilla si el elegido solicitaba, después, un puesto más alto en la jerarquía catedralicia (27).

En el mismo año, unas condiciones parecidas se impusieron en la capilla de los «Reyes Nuevos» de la catedral de Toledo. Allí también, el candidato, incluso el más humilde, sería excluido si era de raza judía o mora. Sin embargo, se encuentra en el documento de esta fundación la primera referencia a solicitudes falsas. Por esta razón, el obispo Silíceo admitió esta misma posibilidad, cuando propuso un estatuto similar para todos los oficios de su catedral. El arzobispo utilizó la imágen de la leche de la madre cuando opinó que los oficios catedralicios no podían darse a los que «todavía tienen en los labios la leche de la reciente perversidad de sus antepasados». De una manera menos convencional hizo una comparación entre la situación de las dignidades catedralicias que trataron de juzgar el origen racial de un candidato al oficio, y la de un comprador de caballos. Como escribió, en 1547, al papa Pablo III, a ese «si le ofrece un caballo imperfecto, aun regalado, no lo aceptará en su cuadra, porque lo que más le importa es la raza del animal» (28). Sin embargo, los argumentos teóricos que se propusieron para justificar la selección de los oficiales según su origen religioso y «racial» fracasaron, cada vez más, en su aplicación teórica, y se vieron suplementados, y aún sustituidos, por consideraciones de carácter totalmente distinto, como puede verse en algunos casos entre las corporaciones del siglo XVI.

Como se indicó anteriormente, el gremio de los candeleros de Barcelona, excluyó, ya en 1498, a los musulmanes, judíos y conversos, así como a sus descendientes. Del mismo modo, los estatutos de 1557 del gremio de cirujanos de la misma ciudad se incorporaba a esta tradición, excluyendo a todos los que descendían de «personas infectas" (con coherencia, los cirujanos utilizan esta imagen venerable), aún bajo la más oscura sospecha, y como resultado de una investigación secreta. No obstante, Molas Ribalta concluyó, en su estudio sobre los gremios barceloneses, que estas corporaciones catalanas emplearon, durante este periodo, un «mecanismo de segregación social que utilizaba la limpieza de sangre o de linaje y el desdén del trabajo manual» (29). La conjunción de estos fenómenos, al parecer distintos, es significativa, en lo que ilustra la manera por la cual las pruebas de hidalguía ofrecian un precedente a las investigaciones de limpieza de sangre. En cada caso, se buscaban datos sobre los padres y abuelos, pero la 
decisión dependia, en la práctica, de la voluntad o falta de ella, de los testigos para sostener al candidato. Claude Chauchadis llega a la misma conclusión al referirse a las cofradías religiosas. Para él, la limpieza de sangre no era más que una de las muchas restricciones que pesaban sobre los que ambicionaban entrar en uno u otro de estos cuerpos píos y caritativos, tales como el dinero, el tiempo disponible, la educación o la cultura, el rango social, y el numerus clausus. Cada vez más, en el caso de dichas cofradías, el precio de las pruebas necesarias reemplazó al objeto pretendido - es decir, la ortodoxia racial y religiosa - como el principal obstáculo práctico contra el ingreso (30).

Podría parecer extraordinario que las corporaciones religiosas, tales como las órdenes militares e incluso la misma Inquisición, no se preocuparan por las leyes de limpieza de sangre en fecha anterior a cerca de 1550. Seguramente fue asi en la venerable orden de Santiago, en la cual la virtud personal era todavía prioritaria, en contra del origen religioso o racial, en los primeros años del reinado de Felipe II, a pesar de que las órdenes de Montesa y Alcántara trataron de excluir a los conversos de sus estatutos en 1468 y 1483 , respectivamente. Incluso más tarde, en la decimosexta centuria, la posesión de la hidalguía parecía tener más importancia, en la práctica, que la limpieza de sangre (31). Este «pragmatismo» superó el año de 1449 y la Sentencia de Pero Sarmiento. Se ha demostrado recientemente que, durante la época en vigor de esta ley, la catedral de Toledo empleó, con satisfacción según parece, a arrendadores judíos, y que algunos de estos reemplazaron a los conversos expulsados de sus puestos por el «Estatuto». Tales acciones sugieren muy poca preocupación por las consideraciones religiosas o raciales (32). Por esta razón, podría parecer menos sorprendente que las pruebas de la «limpieza» de los potenciales familiares del Santo Oficio, que no fueron sistematizadas antes de 1550 , de algunos estatutos catedralicios ya citados, se convirtieron en mecanismos de exclusividad social, más que religiosa o racial. Como concluyó Jean-Pierre Dedieu, sobre el caso de Toledo:

« do not deny that the concept of purity of blood may have played, in the consciousness of the actors, a capital role. But I am oblige to observe that its verification served as the pretext for the putting in place of a test which, more than origins, tested ever more severely the social power of the candidate. It remains to discover why the theological-racial detour through purity of blood was considered necessary" (33).

Con toda probabilidad, estudios futuros confirmarán muchas veces esta conclusión y demostrarán la larga distancia que separó la España del Siglo de Oro de la Alemania de los nazis en su política racial, a pesar de la mezcla 
espantosa de teoría biológica y teológica que afectó igualmente a los educadeos y a los que no tenian educación. Sin embargo, es posible que la preocupación de muchos investigadores contemporáneos, tanto extranjeros como españoles, igual que el estudio tradicional y escelente de la controversia intelectual que rodeaba la cuestión, con el empleo de los estatutos de limpieza de sangre para ocultar la exclusión de individuos por razones totalmente distintas, no llegue a explicar completamente el fenómeno. La investigación, por ejemplo en Córdoba, empieza a desvelar que los criterios de la limpieza de sangre podían emplearse, y de hecho se utilizaban frecuentemente, para incluir, más bien que excluir a la gente. De esta forma, era posible «abandonar» los orígenes judíos o musulmanes, tan fácilmente que, al contrario de lo sucedido en otros casos, dichos orígenes podían recibir publicidad. Se trata, en esta cuestión, de razones personales y pragmáticas, más que ideológicas (34). Es una paradoja histórica que las leyes de limpieza de sangre tuvieran la posibilidad, en sus primeros años de vigencia, de convertirse en un instrumento de la asimilación, además de su propósito explícito de conseguir el «apartamiento» racial, y que, en muchos sitios y casos, se hizo este cambio. 

(1) Impreso para los elegidos a becas del Colegio Mayor de Fonseca en la Universidad de Santiago de Compostela [amablemente provisto por Dr. David Mackenzie].

(2) The Holocaust. Selected documents in eighteen volumes, ed. por John Mendelssohn y Donald E. Detwiler (Nueva York y Londres, 1982), i, pp. 27-30 (texto alemán) y pp. 31 2 (traducción inglesa).

(3) BENITO RUANO, Eloy. Toledo en el siglo XV. Vida política, Madrid, 1961, pp. 191-6, en p. 194.

(4) Ibid., pp. 33-81, con un relato comprehensivo de la revuelta.

(5) SICROFF, Albert A. Los estatutos de limpieza de sangre. Controversias entre los siglos XV y XVII, Madrid, 1985, pp. 51-85.

(6) NIETO CUMPLIDO, Manuel. «La revuelta contra los conversos de Córdoba en 1473«, en Homenaje a Antón de Montoro en el V Centenario de su muerte, Montoro, 1977, pp. 31-49, en pp. 35-6; FARMER, David Hugh. The Oxford Dictionary of Saints, Oxford, 1978, p. 1.

(7) NIETO, «La revuelta», pp. 41-5; EDWARDS, John. Christian Córdoba. The city and its region in the late Middle Ages, Cambridge, 1982, pp. 183-4.

(8) HILLGARTH, J.N. The Spanish kingdoms, 1250-1516, II, Castilian hegemony, 1410-1516, Oxford, 1978, pp. 465-6.

(9) SICROFF, Los estatutos, passim; EDWARDS, «From anti-Judaism to anti-semitism: Juan Escobar del Corro's Tractatus", en Proceedings of the Ninth Worla Congress of Jewish Studies, Division B, The history of the Jewish people from the Second Temple period until the Middle Ages ,Jerusalén, 1986, pp. 143-50.

(10) La preocupación genealógica se ve, por ejemplo, en Génesis, caps. 4-5, 9-11, y en los informes contradictorios sobre los antecesores humanos de Jesucristo, en Mateo, 1:1-17 y Lucas 3:23-28. La punición de los descendientes de los pecadores, a causa de los pecados de sus padres y antepasados, se ve en Deutorónomio 23:3-5, refiriéndose a los Amonitas y a los Moabitas, y la notoria y supuesta confesión, por los judíos, de su culpa comunal y perpetua, de la muerte de Jesús, en Mateo 27:25.

(11) En la historia del paralítico que fue bajado por el techo de una casa para que Jesús le pudiera curar, parece que el Salvador, y también sus adversarios entre los cestudiantes de la Ley y los fariseos", creían que la curación traería forzosamente consigo el perdón de los pecados del enfermo (Lucas 5:17-26).

(12) NOONAN, John T. Contraception. A history of its treatment by the Catholic theologians and canonists, Nueva York, 1965, p. XVII.

(13) Ibid., pp. 116-18; WARNER, Marina. Alone of all her sex. The myth and cult of the Virgin Mary, Londres, 1976, pp. 40-2.

(14) THOMASSET, Claude. “La représentation de la sexualité et de la génération dans le pensée scientifique médiévalem, en Love and marriage in the twelfth century, Medievalia Lovanensia, ser. 1, Studia, VIII, Lovaina, 1981, pp. 1-17. 
(15) Archivo Histórico Nacional de Madrid, Sección Inquisición, leg. 535 núm. 13, citado en SAN. CHEZ MOYA, Manuel, y MONASTERIO ASPIRI, Jasone. «Los judaizantes turolenses en el siglo XV', en Sefarad, XXXII, 1972, p. 335.

(16) KLAPISCH-ZUBER, Christiane. «Blood-parents and milk-parents: wet nursing in Florence, 1300-1530", en Women, family and ritual in Renaissance Italy, trad. de Lydia G. COCHRANE, Chicago, 1987, pp. 132-64, en pp. 161-2.

(17) The Holocaust. Selected documents, XIII, 143-4.

(18) MAC KAY, Angus. "The Hispanic-converso predicament», Transactions of the Royal Historical Society, 5a serie, XXXV, 1985, p. 168.

(19) Dictionnaire des inquisiteurs, Valencia, 1494, ed. por SALA MOLINS, L., París, 1981, citado en RONDIERE LA ROCHE, Josette. "Du discours de l'exclusion des juifs: anti-judaisme ou anti-semitisme?», en Les problèmes de l'exclusion en Espagne (XVleXVIle siècles), París, 1983, pp. 51-75 en p. 62.

(20) PINEDA, Juan de, Diálogos familiares de la agricultura cristiana, III, Biblioteca de Autores Cristianos, CLXII, p. 103b.

(21) CARO BAROJA, Julio. Las formas complejas de la vida religiosa. Religión, sociedad y ca. rácter en la España de los siglos XVI y XVII, Madrid, 1978, p. 489.

(22) MOORE, R.I. The formation of a persecuting society, Oxford, 1987, p. 5; OTIS, Leah L. Prostitution in medieval society. The history of an urban institution in Languedoc, Chicago, 1987, passim; PAGDEN, Anthony. The fall of natural man. The American Indian and the origins of comparative ethnology, 2a edición, Cambridge, 1986, pp. 15-26; THOMAS, Keith. Man and the natural world. Changing attitudes in England, 1500-1800, Harmondsworth, 1984, pp. 17-36.

(23) THOMASSET, La représentation, pp. 9-10.

(24) MOORE, The formation, pp. 61-5.

(25) ARMSTRONG, Karen. The Gospel according to Woman. Christianity's creation of the sex war in the West, Londres, 1987, pp. 1-33; WARNER, Joan of Arc. The image of female heroism, Harmondsworth, 1983, pp. 154-7.

(26) GRACIA BOIX, Rafael. Colección de documentos para la historia de la Inquisición de Córdoba, Córdoba, 1982, pp. 97, 99-101; EDWARDS, «Trial of an inquisitor: the dimissal of Diego Rodríguez Lucero, inquisitor of Córdoba, in 1508", Journal of Ecclesiastical History, XXXVII, 1986, pp. 240-57; Colección de Documentos Inéditos para la Historia de España, CXII, pp. 94-7; REDONDO, Augustin. «Le discours de l'exclusion des 'déviants' tenu par l'Inquisition à l'époque de Charles Quints, en Les problèmes de l'exclusion, pp. 23-49, en p. 31 y nota.

(27) SICROFF, Los estatutos, pp. 120-2.

(28) Ibid., pp. 129-31. Aunque el empleo de la palabra "raza» ya era, evidentemente, convencional en el siglo XVI, en España, así como en otros países, su utilización en este contexto queda oscura.

(29) MOLAS RIBALTA, Pere, "El exclusivismo en los gremios de la Corona de Aragón: limpieza de sangre y limpieza de oficios", Les sociétés fermées dans le monde ibérique (XVle-XVIIle siecles.

(Définitions et problématique (Actes de la table ronde des 8 et 9 février 1985, París, 1986. pp. 69-70, 78 .

(30) CHAUCHADIS, Claude, Les modalités de la fermeture dans les confréries religieuses (XVleXVIle siècle), pp. 83-105, en p. 94.

(31) LAMBERT-GORGES, Martine, «Le bréviaire du bon enquêteur, ou trois siècles d'information sur les candidats à l'habit des ordres militaires», Mélanges de la Casa de Velázquez, XVIII, 1982, pp. 165-98, en pp. 186-8

(32) DUGGAN, Mark, Jewish life in Christian society. The kingdom of Toledo, 1436-51, tesina de Licenciatura, Birmingham, 1987, pp. 41-4.

(33) DEDIEU, Jean-Pierre, «Limpieza, pouvoir et richesse: conditions d'entrée dans le corps des ministres de l'Inquisition (tribunal de Tolède, XVle-XVIle siècle)", Les sociétés fermées, pp. 169 87, en p. 187. 
(34) MARTINEZ BARA, José Antonio, Catálogo de informaciones genealógicas de la Inquisición de Córdoba conservadas en el Archivo Histórico Nacional, Madrid, 1970, dos tomos; EDWARDS, «Los conversos de Córdoba en el siglo XV: un proyecto de la historia social», Andalucia entre oriente y occidente (1236-1492). Actas del V Coloquio Internacional de Historia Medieval de Andalucia (Córdoba, 1986), Córdoba, 1988, pp. 581-4. 